\title{
PARÂMeTROS MORFOLÓGICOS DE MUdAS DE Sesbania virgata (Caz.) Pers E DE Anadenanthera peregrina (L.) CULTIVADAS EM SUBSTRATO FERTILIZADO COM COMPOSTO DE LIXO URBANO ${ }^{1}$
}

\author{
Rafaela Simão Abrahão Nóbrega ${ }^{2}$, Alessandra Monteiro de Paula³ ${ }^{3}$ Rogério Custódio Vilas Boas ${ }^{4}$, Júlio \\ César Azevedo Nóbrega ${ }^{5}$, Fátima Maria de Souza Moreira ${ }^{6}$
}

\begin{abstract}
RESUMO - Objetivou-se avaliar o efeito do composto de lixo urbano nos parâmetros morfológicos de mudas de sesbânia e de angico. Os substratos de cultivo tiveram as seguintes proporções de composto e de amostras de subsolo de Neossolo Quartzarênico ou de Latossolo Vermelho-Amarelo (\%): 0:100; 20:80; 40:60; 60:40 e 80:20, sem a utilização de fertilização mineral. As sementes de sesbânia foram inoculadas com a estirpe recomendada BR 5401. Os parâmetros morfológicos das mudas de sesbânia e angico, suas relações e índice de qualidade de Dickson (IQD) foram determinados aos 56 e 120 dias após a semeadura, respectivamente para cada espécie. Os efeitos dos substratos nos parâmetros morfológicos das mudas de sesbânia e angico variaram de acordo com as proporções do substrato. Para o angico, a adição do composto proporcionou aumento na altura da parte aérea, razão entre massa seca de parte aérea por massa seca de raiz e IQD. Para sesbânia, a adição do composto de lixo ao substrato proporcionou aumento na altura da parte aérea, diâmetro do coleto, massa seca de raiz, da parte aérea e total, razão entre massa seca da parte aérea por massa seca de raiz, IQD e número de nódulos. A obtenção de máxima produção de matéria seca total, diâmetro do coleto e IQD foi de 57:43, sendo, portanto, esta a proporção composta de lixo:solo recomendada para a produção de mudas de sesbânia.
\end{abstract}

Palavras-chave: Adubação, tubete, terra de subsolo, leguminosas e reciclagem de resíduos.

\section{MORPHOLOGICAL PARAMETERS OF Sesbania virgata (CAZ.) PERS AND Anadenanthera peregrina (L.) SEEDLINGS CULTIVATED IN SUBSTRATE FERTILIZED WITH URBAN WASTE COMPOST}

\begin{abstract}
This work aimed to evaluate the effect of urban waste compost on morphological parameters of "sesbania" and "angico" seedlings. The substrates had the following proportion of compost and subsoil samples of Quartz-Sand Neosol or Red-Yellow Latosol (\%): 0:100;20:80; 40:60; 60:40 and 80:20, without mineral fertilizer. Seeds of Sesbania virgata were inoculated with the recommended strain BR 5401. Morphological parameters of seedlings, their relationships and the Dickson Index of Quality (IQD) were determined to "sesbânia" and "angico" at 56 and 120 days after sowing respectively. The substrate effect on morphological parameters of "sesbânia" and "angico" seedlings varied according to substrate proportion. Compost addition caused increase in height, shoot and root dry matter weight ratio and IQD of "angico", therefore not being recommend any one of the substrate proportions to this species. As for "sesbânia", shoot, root and total dry matter weight, stem diameter, shoot area, shoot and root dry matter weight ratio, IQD and number of nodules were directly related to the addition of waste compost to the substrate. Maximum production of total dry matter weight, stem diameter and
\end{abstract}

\footnotetext{
${ }^{1}$ Recebido em 23.04.2007 e aceito para publicação em 19.05.2008.

${ }^{2}$ Departamento de Ciência do Solo da Universidade Federal do Piauí (UFPI), Bom Jesus-PI. E-mail: <rafaela.nobrega@gmail.com>.

${ }^{3}$ Programa de Pós-Graduação em Solos e Nutrição de Plantas da ESALQ/USP. E-mail:<ampaula21@yahoo.com.br>.

${ }^{4}$ Programa de Pós-Graduação em Microbiologia Agrícola do Departamento de Biologia da UFLA. E-mail: $<$ rogeriovilas@gmail.com>

${ }^{5}$ Centro de Ciências Agrárias da Universidade Federal do Piauí, Campus da Socopo, Teresina, PI. E-mail: $<$ jnobrega $>$.

${ }^{6}$ Departamento de Ciência do Solo da UFLA, Cx.P. 37, 37200-000 Lavras, MG. E-mail:<fmoreira@ufla.br>
}

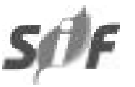

R. Árvore, Viçosa-MG, v.32, n.3, p.597-607, 2008 
IQD were obtained with the proportion 57:43. Thus, we recommend this e proportion of waste compost and soil for the production of "sesbânia" seedlings.

Keywords: Fertilization, tubes, substrate, subsoil, legume species and waste recycling.

\section{INTRODUÇÃO}

O tratamento de resíduos produzidos em áreas urbanas é uma prática crescente, conseqüência da preocupação com a conservação do ambiente, uma vez que a destinação inadequada desses produtos pode resultar em sérios problemas ambientais e de saúde pública. A compostagem tem-se mostrado uma forma de reciclagem de resíduos orgânicos, pois a maior parte da matéria orgânica do lixo pode ser reaproveitada. Esse processo, além de diminuir o volume do lixo, produz como produto final um composto, que pode ser utilizado como insumo agrícola na fertilização do solo (CRAVO et al., 1998). Com isso, tem-se a possibilidade de redução dos gastos com fertilizantes e também de reaproveitar os nutrientes contidos na fração orgânica do lixo (RESENDE, 1991).

A qualidade do composto de lixo é função do tipo de resíduo e processos utilizados na compostagem, no entanto diferentes lotes apresentam como características comuns níveis elevados de matéria orgânica e de teores de macro e micronutrientes. Por isso, o composto de lixo urbano pode ser utilizado para fins agrícola e florestal, desde que se considere na avaliação deles a possível presença de contaminantes, como: metais pesados, teores elevados de sais e outros produtos potencialmente tóxicos (CRAVO et al., 1998; SILVAet al., 2000ab). No entanto, quando se considera o enriquecimento de substratos destinados ao cultivo de mudas de espécies florestais, esse problema não é tão relevante, desde que não afete a qualidade das mudas. Considerando esse aspecto, são necessárias pesquisas para se determinarem as quantidades corretas para compor substratos que garantam mudas de boa qualidade. Assim, a inclusão do composto de lixo como fornecedor de nutrientes para compor substratos visando à produção de mudas arbóreas pode representar alternativa para diminuir os custos de produção destas e, ainda, possibilitar a utilização desse produto em outra atividade, além da aplicação no solo agrícola, o que pode gerar novos mercados para utilização desse tipo de adubo orgânico (ALVES e PASSONI, 1997; COUTINHO et al., 2006).

Para o sucesso de programas de reflorestamento, plantios conservacionistas e r evegetação de áreas degradadas, uma das etapas iniciais é a produção de mudas com qualidade morfofisiológica. Entre os parâmetros morfológicos dessa avaliação, a altura da parte aérea, o diâmetro do coleto, o peso da matéria seca das raízes, da parte aérea e total, além da relação entre esses parâmetros e a utilização de índices de qualidade como o de Dickson, é relevante (DICKSON et al., 1960; CARNEIRO, 1995; FONSECA et al., 2002; SAMÔR et al., 2002; CHAVES e PAIVA, 2004; BERNARDINO et al., 2005; JOSÉ et al., 2005). Contudo, na avaliação da qualidade das mudas se recomenda a utilização de vários parâmetros, uma vez que isolados eles podem não avaliar adequadamente a qualidade delas, a exemplo de mudas muito altas, que geralmente se têm mostrado mais fracas (FONSECA et al., 2002; CHAVES e PAIVA, 2004), fato que compromete o insucesso do plantio.

Pertencentes à família Leguminosae, as espécies Sesbania virgata (Caz.) Pers e Anadenanthera peregrina L. são pioneiras e bastante utilizadas em plantios conservacionistas, conforme relataram Lorenzi (1992) e Davide et al. (1995). Visando contribuir para o conhecimento dessas espécies, este trabalho teve como objetivo avaliar o efeito de substratos contendo composto de lixo urbano em amostras de Neossolo Quartzarênico e de Latossolo Vermelho-Amarelo sob os parâmetros morfológicos destas.

\section{MATERIAL E MÉTODOS}

Instalaram-se dois experimentos, um com angico e outro com sesbânia, em casa de vegetação do Departamento de Ciência do Solo da UFLA, em Lavras, MG. A composição dos substratos, em ambos os experimentos, foram amostras de um Neossolo Quartzarênico (RQ) coletadas na profundidade de 0,20 a 0,50 m, no Município de Lavras, MG, e de um Latossolo 
Vermelho-Amarelo (LVA) coletado na mesma profundidade, no Município de Itumirim, MG, acrescidas de composto de lixo urbano produzido na usina de reciclagem e compostagem de lixo do Município de Alterosa, MG. Esses solos foram escolhidos, pois apresentam textura média (LVA) e arenosa (RQ), e assim buscou-se ter substratos menos compactos e com maior porosidade, após a mistura do composto de lixo ao solo. Foram utilizadas as seguintes proporções de composto de lixo:solo (\%): 0:100; 20:80; 40:60; 60:40; e 80:20, sem a aplicação de fertilizante mineral. Os experimentos foram dispostos em delineamento inteiramente casualizado em esquema fatorial $(2 \times 5) \mathrm{com}$ três repetições. A composição química do composto de lixo e dos solos se encontra no Quadro 1.

A secagem do composto de lixo e do solo foi feita ao ar, espalhando-se os materiais sobre lona plástica, os quais, posteriormente, foram passados em peneira de $4 \mathrm{~mm}$, misturados e acondicionados em tubetes cônicos de $288 \mathrm{~mL}$, conforme recomendado por Samôr et al. (2002). Os tubetes foram alocados em bandejas plásticas com capacidade para 54 unidades e suspensas a $1 \mathrm{~m}$ da superfície do solo.

As sementes de sesbânia foram previamente tratadas com ácido sulfúrico concentrado, $98,08 \%$, por $60 \mathrm{~min}$, lavadas com água destilada e imersas em água por $2 \mathrm{~h}$. Após esse período, semearam-se três sementes por tubete. No momento da semeadura, as sementes de sesbânia foram inoculadas com $5 \times 10^{7}$ células $\mathrm{mL}^{-1}$ da estirpe BR 5401, recomendada como inoculante para essa espécie pela Rede de Laboratórios para Recomendação, Padronização e Difusão de Tecnologia de Inoculantes Microbianos de Interesse Agrícola (RELARE). As sementes de angico foram embebidas em água destilada durante $12 \mathrm{~h}$ e, posteriormente, semeadas, sendo três sementes por tubete.

Quadro 1 - Análise química dos solos e do composto de lixo utilizados para compor o substrato para sesbânia e angico

Table 1 - Chemical analysis of soils and urban waste compost used as substrate for "sesbânia" and "angico' seedling growth

\begin{tabular}{|c|c|c|c|}
\hline Variável $^{(1)}$ & Neossolo Quartzarênico & Latossolo Vermelho- Amarelo & Composto de lixo ${ }^{(2)}$ \\
\hline $\mathrm{pH}\left(\mathrm{H}_{2} \mathrm{O}\right)$ & 5,3 & 5,4 & 7,8 \\
\hline $\mathrm{P}\left(\mathrm{mg} \mathrm{dm}^{-3}\right)$ & 0,9 & 1,7 & 258,0 \\
\hline $\mathrm{K}^{+}\left(\mathrm{mg} \mathrm{dm}^{-3}\right)$ & 14 & 23 & 1300,0 \\
\hline $\mathrm{S}\left(\mathrm{mg} \mathrm{dm}^{-3}\right)$ & 3,3 & 4,9 & 15 \\
\hline $\mathrm{Ca}^{2+}\left(\mathrm{cmol}_{\mathrm{c}} \mathrm{dm}^{-3}\right)$ & 0,5 & 0,5 & 8,3 \\
\hline $\mathrm{Mg}^{2+}\left(\mathrm{cmol}_{\mathrm{c}} \mathrm{dm}^{-3}\right)$ & 0,2 & 0,2 & 3,4 \\
\hline Soma de bases $\left(\mathrm{cmol}_{\mathrm{c}} \mathrm{dm}^{-3}\right)$ & 0,8 & 0,8 & 15 \\
\hline $\mathrm{Al}^{3+}\left(\mathrm{cmol}_{\mathrm{c}} \mathrm{dm}^{-3}\right)$ & 0,9 & 0,2 & 0,1 \\
\hline Acidez potencial $\left(\mathrm{cmol}_{\mathrm{c}} \mathrm{dm}^{-3}\right)$ & 4,5 & 3,2 & 1,1 \\
\hline CTC potencial $\left(\mathrm{cmol}_{\mathrm{c}} \mathrm{dm}^{-3}\right)$ & 5,3 & 4,0 & 16,1 \\
\hline CTC efetiva $\left(\mathrm{cmol}_{\mathrm{c}} \mathrm{dm}^{-3}\right)$ & 1,7 & 1,0 & 15,1 \\
\hline Saturação por $\mathrm{Al}(\%)$ & 54 & 20 & 0,6 \\
\hline Saturação por bases (\%) & 14,4 & 19,6 & 93,1 \\
\hline Matéria orgânica (dag/kg) & 1,0 & 1,0 & 7,6 \\
\hline $\mathrm{Pb}\left(\mathrm{mg} \mathrm{dm}^{-3}\right)$ & - & - & 36,2 \\
\hline $\mathrm{Cu}\left(\mathrm{mg} \mathrm{dm}^{-3}\right)$ & 0,6 & 1,0 & 77,4 \\
\hline $\mathrm{Cd}\left(\mathrm{mg} \mathrm{dm}^{-3}\right)$ & - & - & 4,3 \\
\hline $\operatorname{Mn}\left(\mathrm{mg} \mathrm{dm}^{-3}\right)$ & 3,2 & 2,3 & 253,2 \\
\hline $\mathrm{Zn}\left(\mathrm{mg} \mathrm{dm}^{-3}\right)$ & 0,8 & 0,8 & 230,5 \\
\hline $\mathrm{Ni}\left(\mathrm{mg} \mathrm{dm}^{-3}\right)$ & - & - & 12,5 \\
\hline $\mathrm{Cr}\left(\mathrm{mg} \mathrm{dm}^{-3}\right)$ & - & - & 59,2 \\
\hline $\mathrm{Fe}\left(\mathrm{mg} \mathrm{dm}^{-3}\right)$ & 77,7 & 22,2 & - \\
\hline $\mathrm{B}\left(\mathrm{mg} \mathrm{dm}^{-3}\right)$ & 0,3 & 0,3 & - \\
\hline Areia (\%) & 94 & 70 & - \\
\hline Silte $(\%)$ & 0 & 4 & - \\
\hline Argila (\%) & 6 & 26 & - \\
\hline
\end{tabular}

(1) Análise realizada conforme métodos compilados da EMBRAPA (1997); e (2) Análise realizada conforme métodos compilados de Kiehl (1985).

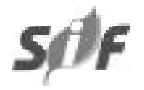

R. Árvore, Viçosa-MG, v.32, n.3, p.597-607, 2008 
A umidade dos substratos foi mantida aproximadamente a $60 \%$ da capacidade de campo, sendo determinada da seguinte forma: para cada proporção do substrato (composto de lixo:solo), em três tubetescontrole de cada tratamento adicionou-se água até a completa saturação e depois se deixou drenar o excesso de água por $24 \mathrm{~h}$. Para evitar a perda de água por evaporação, cada tubete foi coberto em sua parte superior com plástico. Depois desse período, dois tubetes de cada tratamento foram desmontados para a determinação da umidade gravimétrica (valor considerado como umidade na capacidade de campo). Para manter os substratos com o teor de água considerado, foi feito o controle diário da evapotranspiração deles, através de pesagens diárias dos tubetes-controle, sendo a água perdida restituída por irrigações com água deionizada.

Para a análise do crescimento inicial das mudas de sesbânia, após 30 trinta dias, foi feito o desbaste deixando uma planta por tubete e, no final do período de 56 dias da semeadura, as mudas foram coletadas para a determinação da massa seca da parte aérea (MSPA), das raízes (MSR) e total (MST), diâmetro de coleto (D), altura da parte aérea (A), altura da parte aérea por peso da massa seca da parte aérea (A/MSPA) e massa seca da parte aérea por massa seca da raiz (MSPA/ MSR), índice de qualidade de Dickson (IQD) e número de nódulos (NN). No caso do angico, o desbaste foi realizado aos 30 dias da semeadura e as mudas, coletadas aos 120 dias, para avaliação dos mesmos parâmetros citados, à exceção do NN.

O diâmetro de coleto foi medido com paquímetro de precisão de $0,05 \mathrm{~cm}$ e a altura, com régua, tomandose como padrão a gema terminal (meristema apical). A quantificação do peso da matéria seca para a obtenção das relações de massa e dos índices morfológicos foi realizada através da pesagem das partes vegetais após a secagem em estufa a $70{ }^{\circ} \mathrm{C}$ por um período de aproximadamente $72 \mathrm{~h}$ até peso constante. O IQD foi calculado pela fórmula MST/ $(\mathrm{A} / \mathrm{D})+(\mathrm{MSPA} / \mathrm{MSR})$, sendo A em cm e D em mm (DICKSON et al., 1960). O NN foi avaliado através da contagem daqueles, destacando-os das raízes das mudas. Os resultados das variáveis estudadas foram submetidos às análises de variância e de regressão. O programa estatístico utilizado foi o SISVAR 4.2 (FERREIRA, 2003).

R. Árvore, Viçosa-MG, v.32, n.3, p.597-607, 2008

\section{RESULTADOS E DISCUSSÃO}

\subsection{Mudas de angico}

A altura da parte aérea (A) foi influenciada, individualmente, pelo composto de lixo e pelo tipo de solo $(p<0,05)$ utilizado para compor os substratos. $O$ efeito do composto foi linear crescente (Figura 1), enquanto no tipo de solo as plantas cultivadas com RQ apresentaram $12,1 \mathrm{~cm}$ de A e as com LVA, $9,5 \mathrm{~cm}$. Os valores encontrados para essa variável foram inferiores às médias relatadas na literatura para a espécie Anadenanthera macrocarpa (SAMÔR et al., 2002) cultivada com composto de $60 \%$ de cana $+40 \%$ de torta de filtro e aplicação de $0,05 \%$ de N, que apresentaram $26 \mathrm{~cm}$ de A, e as cultivadas com $70 \%$ de casca de eucalipto decomposta $+30 \%$ de vermiculita foram de $27 \mathrm{~cm}$.

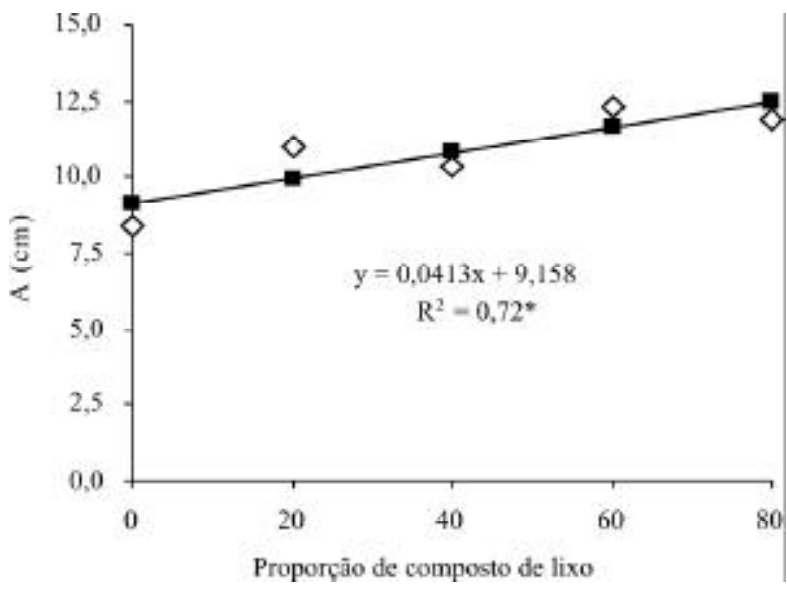

Figura 1 - Variações na altura (A) de mudas de angico em função das proporções de composto de lixo utilizadas para compor o substrato de cultivo.

Figure 1 -Variation in height (A) of "angico" seedlings in relation to the proportions of waste compost in the substrate.

Não houve diferença para o $\mathrm{D}(\mathrm{p}>0,05)$ entre as mudas cultivadas com os substratos contendo LVA $(1,4 \mathrm{~mm})$ e RQ $(1,8 \mathrm{~mm})$. Tais médias se situam abaixo das avaliadas por Samôr et al. (2002), que foram de 3,18 e $3,53 \mathrm{~mm}$ para o Anadenanthera macrocarpa aos 90 dias de cultivo.

Efeito individual do tipo de solo foi verificado em MSPA, e as mudas cultivadas com RQ produziram $0,3 \mathrm{~g} \mathrm{tubete}^{-1} \mathrm{e}$ as com LVA, $0,2 \mathrm{~g}_{\text {tubete }}{ }^{-1}(\mathrm{p}<0,05)$. 
Apesar da baixa concentração dos nutrientes no substrato (0:100) (Quadro 1), as mudas de angico não apresentaram sintoma visual de deficiência nutricional na parte aérea, embora tenham sido menores que as cultivadas com os demais substratos. Tal fato pode ser atribuído, segundo Gross et al. (2004), a capacidade das mudas de se adaptarem às condições edáficas, em geral álicas do cerrado, onde apresentam grande ocorrência. Neste estudo, na proporção de 80:20 (composto de lixo:RQ) foi detectado aparente distúrbio fisiológico nas mudas evidenciado pela alteração visual da pigmentação das folhas em razão, provavelmente, do desbalanço entre macro e micronutrientes e demais elementos químicos ou, também, devido à sensibilidade da espécie a algum elemento químico presente no substrato, que alterou o seu metabolismo.

Para MST foi verificado somente o efeito individual no tipo de solo $(\mathrm{p}<0,05)$, em que as mudas cultivadas no RQ produziram $0,53 \mathrm{~g}$ de tubete $^{-1}$ e as cultivadas com LVA, 0,38 $\mathrm{g}$ de tubete ${ }^{-1}$. Efeito individual entre A/MSPA nos solos $(\mathrm{p}<0,05)$ foi verificado, no RQ de 47,4 e no LVA de 78,5. Apesar de esse quociente apresentar pouca aplicação na avaliação da qualidade de mudas, pode ser usado para predizer seu potencial de sobrevivência, já que, quanto menor for a muda, mais lenhificada ela será (GOMES, 2001; BERNARDINO et al., 2005).

Interação entre os fatores estudados foi verificada na relação MSPA/MSR. Nos substratos contendo LVA foi verificado comportamento quadrático, cuja proporção mínima estimada de substrato foi de 16:84 (composto de lixo:solo) para 0,45 de MSPA/MSR. Nos substratos contendo RQ, essa relação foi linear crescente (Figura 2a). Mesmo comportamento foi verificado para o IQD (Figura 2 b).

Para a MSR foi observado somente efeito individual das proporções de composto de lixo, sendo este linear decrescente (Figura 3). Contudo, apesar de a relação entre doses do composto de lixo e MSR ter se mostrado significativa, o R2 foi muito baixo, fato que compromete o comportamento verificado para a variável. Provavelmente, isso decorre de algum problema no momento da avaliação uma vez que o esperado era a manutenção ou aumento da MSR com o aumento na proporção do composto de lixo nos substratos, conforme verificado nas variáveis (MSPA, MST, D, A, MSPA/MSR, IQD).
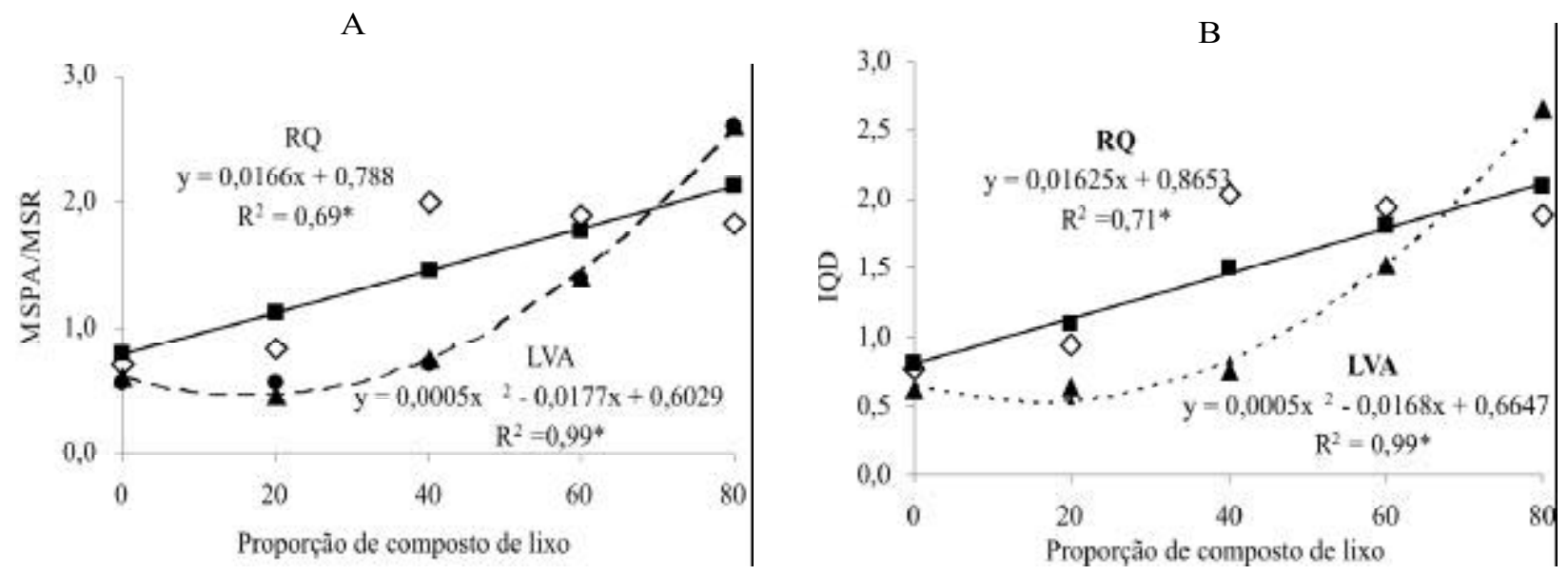

\section{Legenda}

Neossolo Quartzarênico _ - - Latossolo Vermelho Amarelo

Figura 2 - Variações na relação massa seca da parte aérea/massa seca da raiz (MSPA/MSR) (a) e no índice de qualidade de Dickson (IQD) (b) de mudas de angico em função das proporções de composto de lixo utilizadas para compor o substrato de cultivo.

Figure 2 - Variation in the shoot dry mass/root dry mass (MSPA/MSR) ratio (a) and Dickson Index of Quality (IQD) (b) of "angico" seedlings in relation to the proportions of waste compost in the substrate. 


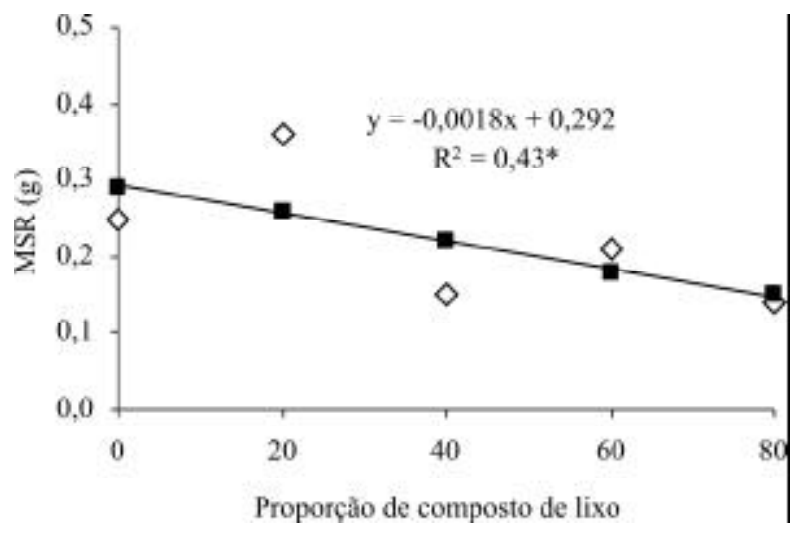

Figura 3 - Variações na massa seca de raiz (MSR) de mudas de angico em função das proporções de composto de lixo utilizadas para compor o substrato de cultivo.

Figure 3 - Variation in root dry weight (MSR) of "angico" seedlings in relation to the proportions of waste compost in the substrate.

\subsection{Mudas de sesbânia}

Para a altura da parte aérea (A) foi verificado somente efeito individual $(\mathrm{p}<0,05)$ do composto de lixo com tendência de aumento desta variável a partir da primeira dose desse composto adicionado ao substrato (20:80) (Figura 4a). Com o acréscimo de nutrientes promovido pelas proporções do composto, as mudas atingiram a máxima estimada de $16,81 \mathrm{~cm}$ na proporção de 61:39 (composto de lixo: solo), seguido de pequena redução após essa proporção, possivelmente devido ao desbalanço de nutrientes no substrato.

$\mathrm{O} \mathrm{D}$, característica morfológica que melhor se correlaciona com parâmetros morfológicos A, MSPA, MSR e MST, segundo José et al. (2005), apresentou efeito individual dos solos e das proporções do composto ( $<<0,05)$. No RQ, o D foi de 3,5 mm e no LVA, de 2,9 $\mathrm{mm}$. Já nas doses do composto de lixo, o efeito foi quadrático e, na proporção de 57:43 (composto de lixo: solo), foi obtido o máximo D de 3,8 mm (Figura 4b), valor esse próximo ao relatado por Samôr et al. (2002) aos 60 dias de cultivo de S.virgata, em que o D foi de 3,98 e 4,09 mm, utilizando-se tubetes de $288 \mathrm{~mL}$ com substrato composto de $60 \%$ de cana $+40 \%$ de torta de filtro e aplicação de $0,05 \%$ de N.

Verificaram-se efeitos individuais dos solos e do composto de lixo, em relação à produção de MSR. Nos substratos contendo RQ foi obtida a média de 0,47 g tubete-1 e no LVA, 0,28 g tubete-1 $(\mathrm{p}<0,05)$. Para o composto de lixo, a máxima produção foi de $0,47 \mathrm{~g}$ tubete1 na proporção de 60:40 (composto de lixo: solo) (Figura $4 \mathrm{c}$ ). Dessa forma, houve proporções que favoreceram o crescimento radicular, e as maiores médias encontradas neste trabalho foram similares às encontradas por Samôr et al. (2002). Tal efeito pode ser atribuído à melhoria da fertilidade do substrato que promoveu o fornecimento de nutrientes e matéria orgânica, estimulando-se com isso, o crescimento radicular das plantas. Coutinho et al. (2005), ao avaliarem o crescimento inicial de mudas de S. virgata plantadas em uma área degradada pela extração de argila, comprovaram o efeito estimulante da adição de composto de lixo com os teores de $\mathrm{Ca}^{2+}$ 9,7 cmolc dm ${ }^{-3} ; \mathrm{Mg}^{2+}$ 2,3 $\mathrm{cmol}_{\mathrm{c}} \mathrm{dm}^{-3} ; \mathrm{P} 1025,0 \mathrm{mg} \mathrm{dm}^{-3}$;

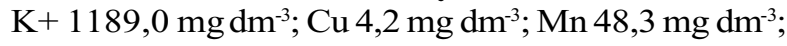

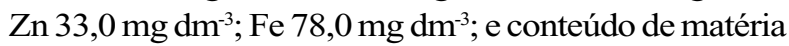
orgânica de 47,6 $\mathrm{g} \mathrm{dm}^{-3}$, nas covas de plantio.

A relação MSPA/MSR apresentou efeito individual dos solos e das proporções de composto de lixo $(p<0,05)$. No RQ foi verificada uma relação de 2,1 e no LVA, de 1,8; no composto, um comportamento linear crescente (Figura 4 d). Para Birchler et al. (1998), essa relação das mudas de Pinus halepensis deve ser, sempre que possível, menor que 2 , sendo essa uma indicação para a maioria das espécies. Assim, a maior e a menor relação obtida neste estudo já exclui as mudas cultivadas com os substratos 80:20 e 0:100 (composto de lixo:solo). No primeiro caso 80:20 (composto de lixo:solo), houve uma desproporção entre a parte aérea e as raízes, indicando, possivelmente, alguma restrição do substrato como desbalanço químico ou problemas físicos que prejudicaram o desenvolvimento das raízes. O maior acúmulo de MSPA pode ser também explicado, em parte, pelo pequeno porte e volume do recipiente, que pode restringir a disponibilidade de água e nutrientes e a expansão do sistema radicular (FONSECA et al., 2002). No segundo caso, 0:100 (composto de lixo:solo), a maior relação pode ser explicada pela pobreza de nutrientes (Quadro 1), uma vez que as raízes se desenvolveram mais que a parte aérea. Isso ocorre comumente em ambientes de baixa fertilidade, o que pode ser uma estratégia da planta para retirar o máximo de nutrientes nessa condição (CALDEIRA et al., 1998). Assim, as mudas dos substratos produzidos nas proporções de 20:80, 40:60 e 60:40 (composto de lixo:solo) tanto para LVAe RQ apresentaram MSPA/MSR dentro dos padrões indicados por Birchler et al. (1998). 

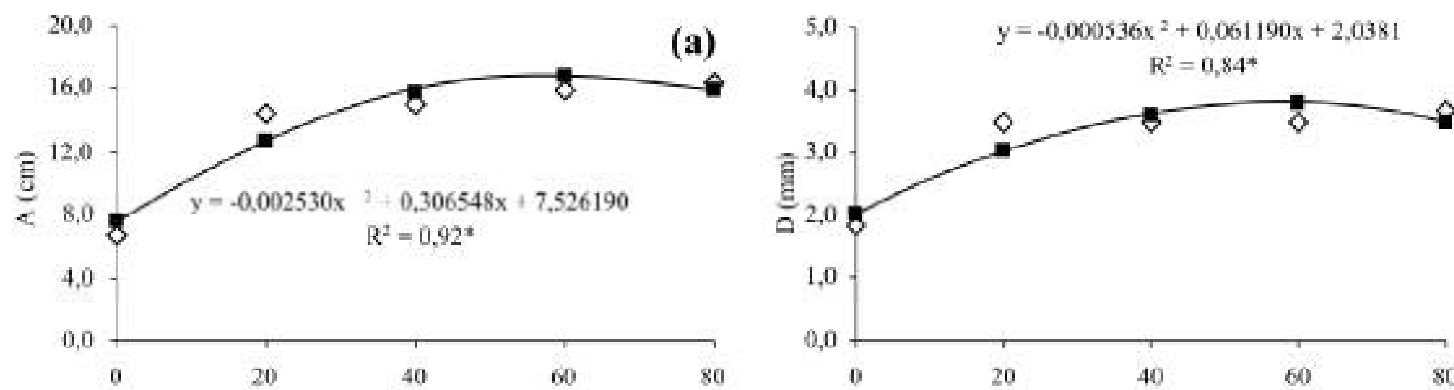

(b)
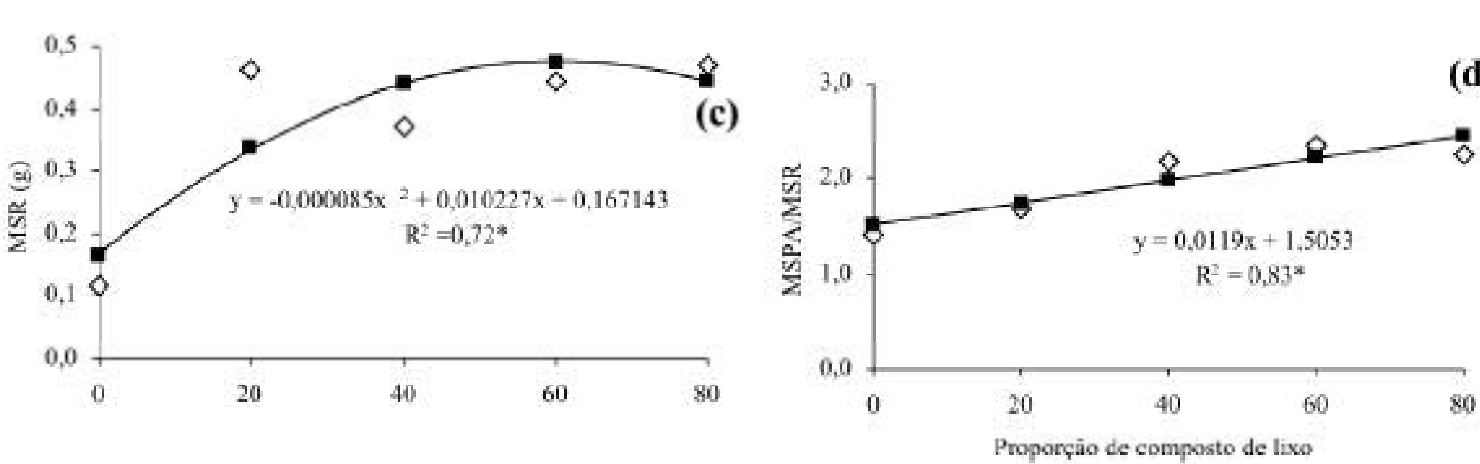

(e)

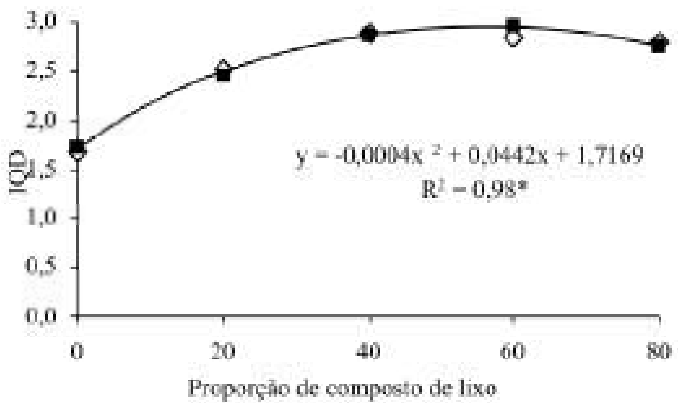

Figura 4 - Variações da altura (A) (a), diâmetro do coleto (D) (b), massa seca de raiz (MSR) (c), relação massa seca da parte aérea/massa seca de raiz (MSPA/MSR) (d) e índice de qualidade de Dickson (IQD) e (e) de mudas de sesbânia em função das proporções de composto de lixo utilizadas para compor o substrato de cultivo.

Figure 4 - Variation in height (A) (a), collar diameter (D) (b), root dry mass (MSR) (c), shoot dry mass/root dry mass (MSPA/MSR) ratio (d) and Dickson Index of Quality (IQD) (e) of "sesbânia" seedlings in relation to the proportions of waste compost in the substrate.

O IQD apresentou efeito individual somente no composto de lixo, tendo na proporção de 57:43 (composto de lixo:solo) o índice máximo de 2,97 (Figura 4e). Na proporção de 57:43 (composto de lixo:solo), houve incremento de 73,7\% do IQD, em relação à média encontrada no substrato com 0:100 (composto de lixo:solo). Tal resultado está de acordo com trabalhos de Alves e Passoni (1997) e Coutinho et al. (2006), que têm apontado efeito benéfico da utilização do composto de lixo para compor substratos para mudas de diferentes espécies arbóreas na fase de viveiro.

Na MSPA foi verificada interação entre os fatores estudados, com comportamento quadrático para o $\mathrm{RQ}$, cuja proporção máxima estimada foi de 57:43 (composto de lixo:solo) para a produção de $1,4 \mathrm{~g}$ tubete $^{1}$ (Figura 5 a) e linear crescente para o LVA. Novamente, as mudas cultivadas com RQ tiveram maiores médias que as cultivadas com LVA.

R. Árvore, Viçosa-MG, v.32, n.3, p.597-607, 2008 
Para MST foi verificado o mesmo comportamento da MSPA, ou seja, quadrático para RQ, com a proporção estimada de 57:43 (composto de lixo:solo) para $2 \mathrm{~g}$ tubete $^{-1}$ e linear crescente para LVA (Figura 5b).

Para a relação A/MSPA foi verificada interação entre os fatores estudados. A proporção mínima estimada para o RQ foi de 55:45 (composto de lixo:solo) para a obtenção de 11,51 , e para o LVA esta foi de 64:36 (composto de lixo:solo) para obtenção de 17,37 (Figura 5c).

Considerando que o NN é conseqüência da densidade de bactérias que se estabeleceram nos substratos, este representa uma medida semiquantitativa do número de células presentes. Assim, para o NN obtido nas mudas de sesbânia houve efeito individual do solo ( $\mathrm{p}<0,05)$, em que a maior média (71) foi registrada em RQ, em comparação com LVA, que apresentou 19 nódulos. Tal resultado pode ser atribuído à granulometria do substrato composto de RQ, uma vez que os solos de textura mais arenosa proporcionaram um meio mais poroso, que favorece a maior aeração e infiltração de

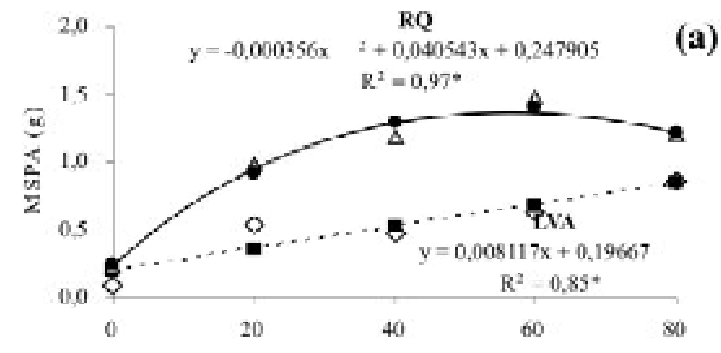

(c)

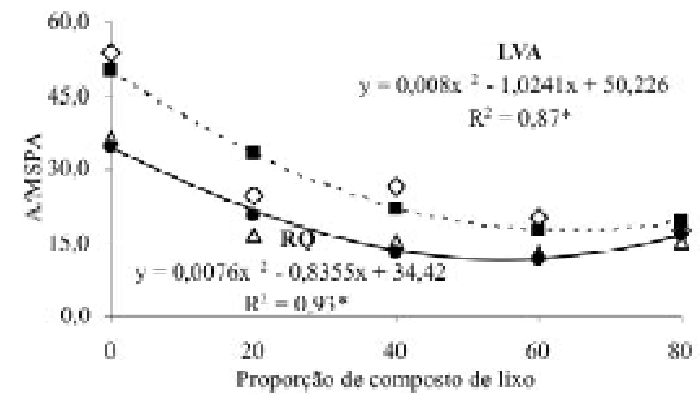

água no tubete e, conseqüentemente, um melhor desenvolvimento radicular e, também, da nodulação. Além do solo, foi verificado também efeito individual do composto de lixo sobre a nodulação, uma vez que na proporção de 47:53 se estimaram 106 nódulos (Figura 6). A densidade de bactérias que nodularam a sesbânia, acima da proporção de substrato máxima estimada, foi bem reduzida, e os nódulos coletados nas raízes apresentaram-se pequenos e esbranquiçados quando esmagados, indicando ausência de legemoglobina. Tal fato pode ser atribuído ao baixo requerimento por $\mathrm{N}$, que não foi considerado um fator limitante nessas condições (MOREIRA e FRANCO, 1994), já que o composto de lixo é um material rico em matéria orgânica, e isso desfavorece a simbiose entre a planta e a bactéria, condicionando as células a se adaptarem às condições saprofíticas nos substratos. Mesmo cultivada em substrato rico em matéria orgânica, as mudas de sesbânia foram capazes de nodular. Isso é importante em condições de campo, pois as mudas noduladas já apresentam uma vantagem para se estabelecerem no campo, devido à aquisição de nitrogênio através da fixação biológica.

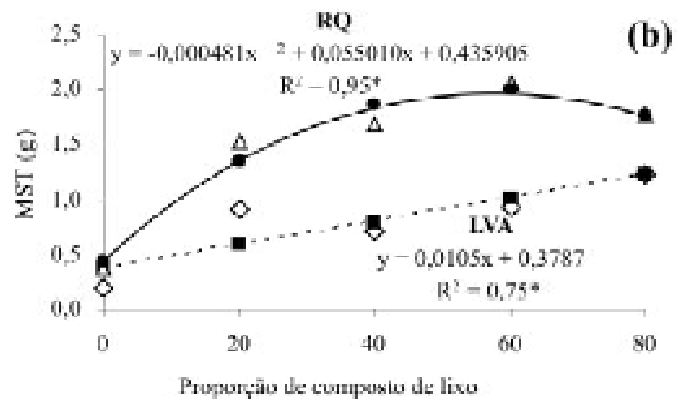

\author{
Legendu \\ RQ: Neossolo Quartzarénico \\ -.-. LVA: Latossolo Vermello Amarelo
}

Figura 5 - Variações da massa seca da parte aérea (MSPA) (a), massa seca total (MST) (b) e relação altura/massa seca da parte aérea (A/MSPA) (c) de mudas de sesbânia em função das proporções de composto de lixo utilizadas para compor o substrato de cultivo.

Figure 5 - Variation in shoot dry mass (MSPA) (a), total dry matter (MST) (b) and height/ shoot dry mass (A/MSPA) (c) of "sesbania" seedlings in relation to the proportions of waste compost in the substrate.

R. Árvore, Viçosa-MG, v.32, n.3, p.597-607, 2008

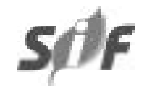


Com os resultados das duas espécies estudadas, pode-se constatar que as que foram cultivadas com o substrato contendo composto de lixo apresentaram influência $(p<0,05)$ nos parâmetros morfológicos avaliados, em relação às que foram cultivadas somente com as amostras de LVA e RQ (0:100) (composto de lixo:solo). Essa influência pode estar relacionada aos macronutrientes fornecidos pelo composto de lixo, destacando-se o $\mathrm{P}, \mathrm{K}^{+}, \mathrm{Ca}^{2+} \mathrm{e} \mathrm{Mg}^{2+}$ considerados baixos (0:100) no RQ e LVAe que, portanto, não foram suficientes para suprir as necessidades das espécies durante a fase de mudas (Quadro 1). Esses nutrientes possivelmente se encontram em teores adequados para o desenvolvimento das mudas de sesbânia na proporção de 57:43 (composto de lixo:solo), uma vez que nessa proporção se obtiveram as médias máximas dos parâmetros morfológicos avaliados D, MSPA, MST e IQD. Acrescentase, ainda, que a adição de material orgânico ao solo, além do efeito direto no fornecimento de nutrientes das plantas, melhora as condições físicas e biológicas do solo, contribuindo também para a redução dos teores de $\mathrm{Al}$ trocável (SIDIRAS e PAVAN, 1985; PAVAN et al., 1986) e aumento da CTC, sendo, portanto, uma variável indicadora da retenção de água e de nutrientes nos substratos.

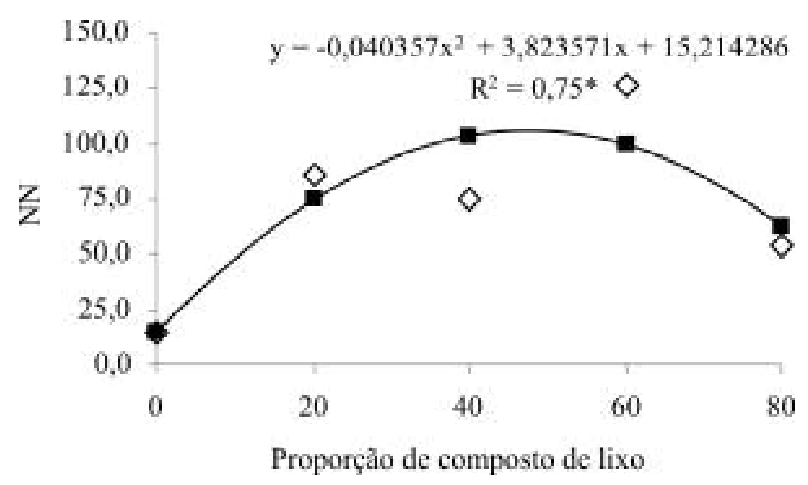

Figura 6 - Número de nódulos (NN) de mudas de sesbânia em função das proporções de composto de lixo utilizadas para compor o substrato de cultivo.

Figure 6-Number of nodules (NN) of "sesbânia" seedlings in relation to the proportions of waste compost used to make the substrate.

As mudas de sesbânia e angico cultivadas com substrato composto de RQ, no geral, apresentaram maiores valores dos parâmetros morfológicos que as cultivadas com LVA. A diferença entre os dois tipos de solo pode ser atribuída, provavelmente, ao efeito físico do substrato proporcionado pela textura mais arenosa do RQ, que possivelmente proporcionou um substrato menos compacto, com maior porosidade (BRANDÃO et al., 2003), que favorece a maior aeração no tubete, o maior crescimento radicular e, com isso, a maior absorção de nutrientes pelas mudas.

Para o angico, considerando o valor ótimo e equilibrando todos os parâmetros morfológicos avaliados, a proporção de 60:40 (composto de lixo: Neossolo) pode ser sugerida para estudos posteriores com a espécie. As proporções de substrato para o cultivo da sesbânia variaram entre 55:45 e 64:36 (composto de lixo:solo). Na proporção de $57: 43$, houve produção máxima dos parâmetros D, MSPA, MST e IQD. Como o IQD pondera os resultados de vários parâmetros importantes (FONSECA et al., 2002) e quanto maior seu valor, melhor a qualidade de mudas (GOMES, 2001; BERNADINO et al., 2005), a proporção de 57:43 (composto de lixo:solo) é a mais indicada para o crescimento inicial das mudas de sesbânia.

\section{CONCLUSÕES}

1 - A adição do composto ocasionou aumento na altura, relação massa seca de parte aérea por massa seca de raiz e no índice de qualidade de Dickson nas mudas de angico, sendo a proporção de 60:40 (composto de lixo: Neossolo) sugerida para estudos posteriores com a espécie.

2 - Para a sesbânia, a adição do composto de lixo ao substrato proporcionou aumento na altura da parte aérea, diâmetro do coleto, massa seca de raiz, parte aérea e total, relação massa seca de parte aérea sob massa seca de raiz, índice de qualidade de Dickson e número de nódulos.

3 - A obtenção de máxima produção de matéria seca total, diâmetro do coleto e índice de qualidade de Dickson foi com a proporção 57:43 (composto de lixo: solo), sendo esta a recomendada para o crescimento inicial das mudas de sesbânia.

\section{REFERÊNCIAS}

ALVES, W.L.; PASSONI, A.A. Composto e vermicomposto de lixo urbano na produção de mudas de oiti (Licania tomentosa (Benth)) para arborização. Pesquisa Agropecuária Brasileira, v.32, n.10, 1997.

R. Árvore, Viçosa-MG, v.32, n.3, p.597-607, 2008 
BERNARDINO, D.C.S. et al. Crescimento e qualidade de mudas de Anadenanthera Macrocarpa (Benth.) Brenan em resposta à saturação por bases do substrato. Revista Árvore, v.29, n.6, p.863-870, 2005.

BIRCHLER, T. et al. La planta ideal: revision del concepto, parámetros definitorios e implementaction practica. Investigacion

Agraria, Sistemas y Recursos

Forestales, v.7, n.1/2, p.109-121, 1998.

BRANDÃO, V.S. et al. Infiltração da água no solo. Viçosa, UFV, 2003.98 p.

CALDEIRA, M.V.W. et al. Crescimento de mudas de Eucalyptus saligna Smith em função de diferentes doses de vermicomposto. Revista Floresta, v.28, p.19-30. 1998.

CARnEIRO, J.G.A. Produção e controle de qualidade de mudas florestais. Curitiba: UFPR/FUPEP, 1995. 451 p.

CHAVES, A.S.; PAIVA, H.N. Influência de diferentes períodos de sombreamento sobre a qualidade de fedegoso (Senna macranthera (Collad.) Irwin et Barn. Scientia Forestalis, n.65, p.22-29, 2004.

COUTINHO, M.P. et al. Crescimento de mudas de Sesbania virgata (Cav.) Pers. plantadas em uma área degradada por extração de argila. Floresta, v.35, n.2, p.231-239, 2005.

COUTINHO, M.P. et al. Substrato de cavas de extração de argila enriquecido com subprodutos agroindustriais e urbanos para produção de mudas de sesbânia. Revista Árvore, v.30, n.1, p.147-153, 2006.

CRAVO, M.S. Caracterização química de compostos de lixo de algumas usinas brasileiras. Revista Brasileira de Ciência do Solo, v.22, n.3, p.547-553, 1998.

DAVIDE, A.C.; FARIA, J.M.R.; BOTELHO, S.A. Propagação de espécies florestais. Belo Horizonte: CEMIG/UFLA/FAEPE, 1995. 40p.

R. Árvore, Viçosa-MG, v.32, n.3, p.597-607, 2008
DICKSON, A.; LEAF, A.; HOSNER, J.F. Quality appraisal of white spruce and white pine seedling stock in nurseries. Forestry chronicle, v.36, p.10-13, 1960.

\section{EMPRESABRASILEIRADEPESQUISA}

AGROPECUÁRIA-EMBRAPA. Centro Nacional de Pesquisa de Solos. Manual de métodos de análise de solo. $2^{\mathrm{a}}$ ed. Rio de Janeiro: 1997. 212p.

FERREIRA, D.F. SisVar - programa estatístico. Versão 4.2 (Build 39). Lavras: Universidade Federal de Lavras, 1999-2003.

FONSECA, E.P. et al. Padrão de qualidade de mudas de Trema micrantha (L.) Blume produzidas sob diferentes períodos de sombreamento.

Revista Árvore, v.26, n.4, p.515-523, 2002.

GOMES, J.M. Parâmetros morfológicos na avaliação da qualidade de mudas de Eucalyptus grandis, produzidas em diferentes tamanhos de tubete e de dosagens de N-P-K. 2001. 166p. Tese (Doutorado em Ciência Florestal) - Universidade Federal de Viçosa, Viçosa, 2001.

GROSS, E.; CORDEIRO, L., CAETANO,F.H.Nodulação e micorrização em Anadenanthera peregrina VAR. falcata em solo de cerrado autoclavado e não autoclavado. Revista Brasileira da Ciência do Solo, v.28, p.95-101, 2004.

JOSÉ, A.C.; DAVIDE, A.C.; OLIVEIRA, S.L. Produção de mudas de aroeira (Schinus terebynthifolius Raddi) para recuperação de áreas degradadas pela mineração de bauxita. Cerne, v.11, n.2, p.187-196, 2005.

KIEHL, E.J. Fertilizantes orgânicos. São Paulo, Agronômica Ceres, 1985. 492 p.

LORENZI, H. Árvores brasileiras: manual de identificação e cultivo de plantas arbóreas nativas do Brasil. Nova Odessa, Plantarum, 1992. 352p.

MOREIRA, F.M.S; FRANCO, A.A. Rhizobia Host interactions in tropical ecosystems in Brazil. In: SPRENT, J.I.; D.Mc KEY (eds.) Advances in legume systematic 5: The nitrogen factor, p.63-74, 1994. 
PAVAN, M.A. et al. Manejo da cobertura do solo para formação e produção de uma lavoura cafeeira. I. Influência na fertilidade do solo. Pesquisa Agropecuária Brasileira, v.21, n.2, p.187-192, 1986.

RESENDE, A.A.P. Estudo e avaliação de um processo de reciclagem e compostagem dos resíduos sólidos urbanos. 1991. 151p. Dissertação (Mestrado em Ciência do Solo) - Belo Horizonte, UFMG.

SAMÔR, O.J.M. et al. Qualidade de mudas de angico e sesbânia produzidas em diferentes recipientes e substratos. Revista Árvore, v.26, n.2, p.209-215, 2002.
SIDIRAS, N.; PAVAN, M.A. Influência do sistema de manejo do solo no seu nível de fertilidade.

Revista Brasileira da Ciência do Solo, v.9, n.3, p.249-254, 1985.

SILVA, F.C. et al. Uso agrícola de composto de lixo: efeito do tempo de incubação solo/resíduo na disponibilidade de metal pesado. Comunicado técnico da Embrapa Informática na Agropecuária. n.10, dez. 2000. 8p.

SILVA, F.C. et al. Uso agrícola de composto de lixo: efeito do tempo de incubação solo/resíduo na disponibilidade de micronutrientes. Comunicado técnico da Embrapa Informática na Agropecuária. n.11, dez. 2000. 7p. 